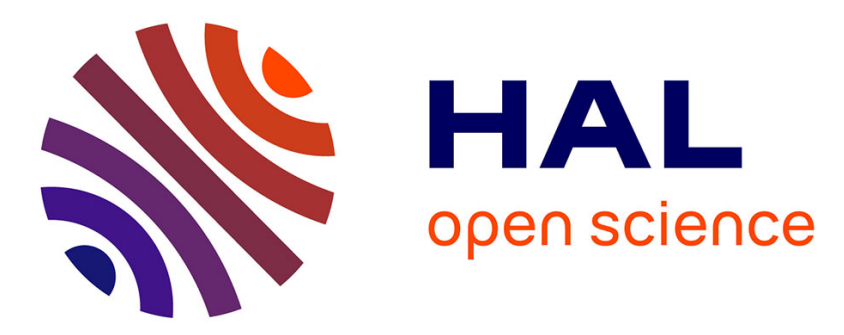

\title{
Coordination Chemistry Inside Polymeric Nanoreactors: Interparticle Metal Exchange and Ionic Compound Vectorization in Phosphine-Functionalized Amphiphilic Polymer Latexes
}

Si Chen, Florence Gayet, Eric Manoury, Ahmad Joumaa, Muriel Lansalot, Franck d'Agosto, Rinaldo Poli

\section{To cite this version:}

Si Chen, Florence Gayet, Eric Manoury, Ahmad Joumaa, Muriel Lansalot, et al.. Coordination Chemistry Inside Polymeric Nanoreactors: Interparticle Metal Exchange and Ionic Compound Vectorization in Phosphine-Functionalized Amphiphilic Polymer Latexes. Chemistry - A European Journal, 2016, 22 (18), pp.6302-6313. 10.1002/chem.201504923 . hal-01877396

\author{
HAL Id: hal-01877396 \\ https://hal.science/hal-01877396
}

Submitted on 29 Jul 2021

HAL is a multi-disciplinary open access archive for the deposit and dissemination of scientific research documents, whether they are published or not. The documents may come from teaching and research institutions in France or abroad, or from public or private research centers.
L'archive ouverte pluridisciplinaire HAL, est destinée au dépôt et à la diffusion de documents scientifiques de niveau recherche, publiés ou non, émanant des établissements d'enseignement et de recherche français ou étrangers, des laboratoires publics ou privés. 


\title{
Coordination chemistry inside polymeric nanoreactors:
}

\section{interparticle metal exchange and ionic compound vectorization in phosphine-functionalized amphiphilic polymer latexes}

\author{
Si Chen, ${ }^{\left[{ }^{[a]}\right.}$ Florence Gayet, ${ }^{[a]}$ Eric Manoury, ${ }^{[a]}$ Ahmad Joumaa, ${ }^{[a]}$ Muriel Lansalot, ${ }^{[b]}$ Franck D'Agosto ${ }^{[b]}$ \\ and Rinaldo Poli ${ }^{*[a, c]}$
}

\begin{abstract}
Stable latexes of hierarchically organized core-cross-linked polymer micelles, functionalized at the core by triphenylphosphine (TPP@CCM), have been investigated by NMR at both natural (ca. 5) and strongly basic $\mathrm{pH}$ (13.6) after core swelling with toluene. The core-shell interface structuring forces part of the hydrophilic PEO chains to reside inside the hydrophobic core at both $\mathrm{pH}$. Loading the particle cores with $\left[\mathrm{Rh}(\mathrm{acac})(\mathrm{CO})_{2}\right]$ at various $\mathrm{Rh} / \mathrm{P}$ ratios yielded polymer-supported $[\mathrm{Rh}(\mathrm{acac})(\mathrm{CO})(\mathrm{TPP})]$. The particle-to-particle rhodium migration is very fast at natural $\mathrm{pH}$ but slows down dramatically at high $\mathrm{pH}$, while the size distribution of the nanoreactors remains unchanged. The slow migration at $\mathrm{pH} 13.6$ leads to the generation of polymer-anchored $\left[\mathrm{Rh}(\mathrm{OH})(\mathrm{CO})(\mathrm{TPP})_{2}\right]$, which is also generated immediately upon $\mathrm{NaOH}$ addition to the $50 \%$ $[\mathrm{Rh}(\mathrm{acac})(\mathrm{CO})]$-loaded particles. Similarly, treating the same particles with $\mathrm{NaCl}$ yielded polymer-anchored $\left[\mathrm{RhCl}(\mathrm{CO})(\mathrm{TPP})_{2}\right]$. Interparticle coupling occurs during these rapid processes. These experiments prove that the major contribution to metal migration is direct core-core contact. The slow migration at high $\mathrm{pH}$, however, must result from a pathway not involving core-core contact. The facile penetration of the polymer cores by $\mathrm{NaOH}$ and $\mathrm{NaCl}$ results from the presence of shelllinked poly(ethylene oxide) methyl ether functions both outside and inside the polymer core-shell interface.
\end{abstract}

\section{Introduction}

Molecular dynamics in colloidal dispersions has been intensively investigated, notably in relation to Ostwald ripening leading to emulsion coarsening, ${ }^{[1]}$ but there are still open questions on the mechanism at the molecular level. For instance, a new mechanism in addition to droplet fusion (coalescence) and molecular exchange through the continuous phase (Ostwald ripening) has been recently demonstrated. ${ }^{[2]}$ This new mechanism,

\footnotetext{
[a] Dr. S. Chen, Dr. F. Gayet, Dr. E. Manoury, Mr. A. Joumaa, Prof. R. Poli

CNRS, LCC (Laboratoire de Chimie de Coordination)

Université de Toulouse, UPS, INPT,

205 Route de Narbonne, BP 44099, F-31077, Toulouse Cedex 4

France

E-mail: rinaldo.poli@lcc-toulouse.fr

[b] Dr. M. Lansalot, Dr. F. D‘Agosto

CNRS, UMR 5265, C2P2 (Chemistry, Catalysis, Polymers \&

Processes), Team LCPP

Université de Lyon, Univ. Lyon 1, CPE Lyon

69616 Villeurbanne, France

[c] Prof. R. Poli

Institut Universitaire de France,

103, bd Saint-Michel, 75005, Paris, France
}

Supporting information for this article is given via a link at the end of the document. termed "contact ripening", involves molecular exchange between two droplets only upon contact, without leading to coalescence.

The droplets dispersed in a continuous fluid phase can be reduced in size using high concentrations of low molar mass surfactant to yield micelles, more or less swollen by the dispersed phase. Reducing the amount of dispersed phase to the zero limit leaves a dispersion of unswollen micelles. One important property of micellar dispersions, whether swollen or not, is the dynamic exchange with free surfactant molecules. A colloidal dispersion is therefore a very complex medium with migration of both surfactant molecules and dispersed phase molecules from droplet to droplet and to the continuous phase. A simplification of this system can be achieved by moving from low molar mass surfactants to amphiphilic macromolecules and then further by cross-linking the arms together, either at the core or at the shell level, turning the self-assembled multimolecular object into a unimolecular version. This removes any dynamic exchange of the surfactant molecules while it retains the possibility of hosting a dispersed phase, although the swelling capacity becomes physically limited.

Controlled radical polymerization has proven efficient to access a vast range of amphiphilic block copolymers that can further be assembled into unimolecular cross-linked micelles with amphiphilic arms that are characterized by controlled size, composition and cross-linking density and with narrow size distributions. Physical chemistry studies of colloidal dispersions of such unimolecular nano-objects are in their infancy and dynamic processes of small molecules contained inside such nano-objects have not been addressed to the best of our knowledge. We do so here, using rhodium coordination compounds and phosphinefunctionalized cross-linked micelles.

Table 1. Polymer latexes used in this study. ${ }^{[a]}$

\begin{tabular}{lllllll}
\hline & \multirow{2}{*}{$\times$} & \multicolumn{2}{c}{$D_{z}(\mathrm{~nm}) / \mathrm{PDI}$} & $\begin{array}{c}\text { Solid } \\
(\%)^{[\mathrm{b}]}\end{array}$ & $\begin{array}{c}\text { [DPPS] } \\
(\mathrm{mol} / \mathrm{L})^{[\mathrm{c}]}\end{array}$ & Ref. \\
\cline { 3 - 6 } & & $\mathrm{H}_{2} \mathrm{O}$ & $\mathrm{THF}$ & & \\
\hline TPP@CCM-1 & 0.05 & $100 / 0.28$ & $163 / 0.07$ & 25.6 & 0.060 & ${ }^{[3]}$ \\
TPP@CCM-2 & 0.10 & $106 / 0.24$ & $220 / 0.07$ & 28.1 & 0.12 & ${ }^{[3]}$ \\
TPP@CCM-3 & 0.25 & $73 / 0.09$ & $235 / 0.20$ & 27.4 & 0.29 & ${ }^{[4]}$ \\
\hline
\end{tabular}

[a] CCM: $\mathrm{HOOCCH}_{2} \mathrm{CH}_{2} \mathrm{C}(\mathrm{CN})(\mathrm{Me})-\left[\mathrm{MAA}_{15}-\mathrm{Co}-\mathrm{PEOMA} \mathrm{A}_{15}\right]-b$-[S $\mathrm{S}_{(1-\mathrm{x})}-\mathrm{CO}-$ $\left.(\text { DPPS })_{\times}\right]_{300} b-\left[\mathrm{S}_{90}-c 0-D E G D M A_{10}\right]-S C(S) S P r$. Abbreviations: $M A A=$ methacrylic acid; PEOMA = poly(ethylene oxide) methacrylate (average degree of polymerization of PEO $=19) ; S=$ styrene; DPPS $=p$ diphenylphosphinostyrene. ${ }^{[b]}$ Weight percent of polymer in the latex. ${ }^{[c]}$ Molar concentration of polymer-grafted phosphine in the latex.

The polymers used for these studies are core-cross-linked micelles (CCM), a new type of catalytic nanoreactors recently developed in our laboratories and used for the efficient hydroformylation of 1-octene under aqueous biphasic

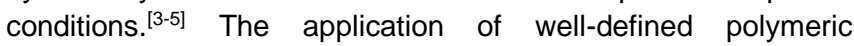
nanoreactors to catalytic transformations is attracting growing 
attention. ${ }^{[6]}$ The CCMs that we have developed function with the catalytic event taking place within the hydrophobic micellar core, rather than at the core-shell interface as often exploited in aqueous biphasic catalysis of interfacial type carried out with the help of surfactants. ${ }^{[7]}$ Other recent contributions to this area have involved polymers with a different architecture than our CCMs, either cross-linked at the outer shell ${ }^{[8]}$ or in an intermediate corona, ${ }^{[9]}$ or with a fully cross-linked nanogel core. ${ }^{[10]}$ The investigations presented here were stimulated by our desire to understand the origin of the metal leaching observed during catalytic applications with our CCM nanoreactors. A small but non negligible concentration of rhodium, down to $1.7 \mathrm{ppm}$, was measured in the recovered organic phase and remained approximately constant in subsequent recycles with the same catalyst batch. ${ }^{[4]} \mathrm{A}$ dynamic light scattering (DLS) analysis of the recovered organic phases revealed the presence of both individual and aggregated particle populations, ${ }^{[4-5]}$ suggesting transfer of the whole nanoreactors to the organic phase as the main cause of leaching. Smaller objects, as could for instance be produced by shear fragmentation of the polymer scaffold, were not detected. However, the possibility that rhodium complexes could also be lost from the nanoreactor core in a molecular form could not be excluded. Therefore, the coordination chemistry studies reported here, involving metal migration from fully metalloaded polymer particles to unloaded ones, were meant to probe the possible extraction of rhodium from the nanoreactors in a molecular form.

The results of the investigation, in addition to addressing this specific question, have also revealed the role of core-core contact during particle interpenetration as a major mechanism for interparticle metal migration and an unexpectedly facile vectorization of ionic inorganic compounds $(\mathrm{NaX}, \mathrm{X}=\mathrm{Cl}, \mathrm{OH})$ to the hydrophobic nanoreactor core, a phenomenon that has relevance to the ionic compound transport mechanism across biological membranes and introduces interesting perspectives for additional catalytic applications.

\section{Results and Discussion}

a) NMR properties of TPP@CCM at natural and at high pH: structuring of the core-shell interphase.
The polymers used for the present study, symbolized as TPP@CCM, are well-defined unimolecular core-cross-linked micelles (CCM) functionalized by triphenylphosphine (TPP) ligands that are covalently linked to the hydrophobic polystyrene core. Their synthesis, accomplished by a three-step-one-pot RAFT polymerization in water by virtue of the "polymerizationinduced self-assembly" (PISA), has been previously reported. ${ }^{[3-4]}$ For practical reference, the molecular structure is presented in Figure 1 together with a pictorial representation of the structural organization. The TEM and DLS characterization demonstrates the well-defined spherical shape and narrow size distribution of the polymer particles (see details in Table 1). The $\mathrm{pH}$ measured for this latex, as obtained from synthesis, is ca. 4.9 and up to 5.5 after dilution by a factor of 3 . Under these conditions, the majority of the carboxylic acid functions are undissociated. This is what will be henceforth referred to as "natural $\mathrm{pH}$ ".

The NMR properties of the latex at the natural $\mathrm{pH}$ have also been previously reported,,${ }^{[3]}$ but their interpretation in terms of the core-shell interface structuring merits a deeper discussion because this structuring is important to understand the new phenomena discussed in the present contribution. The NMR properties are recalled in the supplemental figure $\mathrm{S} 1$. The polymer core is invisible in $D_{2} \mathrm{O}$ where it is not solvated but becomes observable in THF- $\mathrm{D}_{8}$ and also after core swelling with a suitable organic solvent such as toluene. All CCM samples gave identical results. For the toluene-swollen sample, the PEO resonances are split into two sets: a sharper one associated to the more mobile PEO chains in an aqueous environment and a broader one associated to less mobile chains placed inside the hydrophobic core. Line deconvolution as the sum of two Lorentzians and integration (figure S2) gives only $30.3 \%$ of water-solvated PEO chains and $69.7 \%$ in the hydrophobic core. This result is unexpected and remarkable because PEO homopolymers partition essentially quantitatively in favor of the aqueous phase when placed in a water-toluene biphasic medium at room temperature. ${ }^{[11]}$ Another remarkable observation is that the methacrylic Me protons of the "hydrophilic" P(MAA-co-PEOMA) shell are not visible in $\mathrm{D}_{2} \mathrm{O}$, whether the polymer core is tolueneswollen or not, but are visible in THF-D 8 ( $\delta 2.54)$.

These two observations lead us to propose the model shown in Figure 2 for the structuring of the core-shell interphase. The shell $\mathrm{P}$ (MAA-co- PEOMA) backbone is not sufficiently solvated
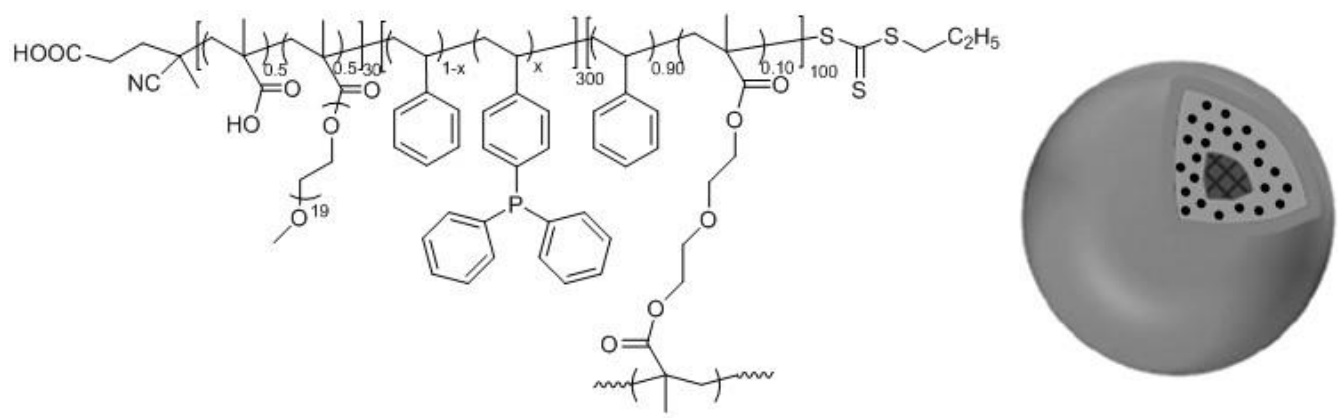

Figure 1. Chemical formula and representation of the TPP@CCM polymer architecture. 
neither by water nor by toluene, thus lies as a less mobile interphase layer between the water solution and the tolueneswollen core. The random conformation of the backbone is organized in such a way that part of the PEO and methacrylic acid function are facing the water solution whereas another part is forced to be placed inside the hydrophobic core. It is therefore the lack of solvation of the shell backbone and the associated enthalpic gain of the interlayer structuring that pays the penalty of placing part of the PEO chains in the less favorable hydrophobic core environment. The NMR properties of TPP@CCM have now also been investigated at high $\mathrm{pH}$, where the polymer hydrophilic shell is completely deprotonated. The $\mathrm{pK}_{\mathrm{a}}$ of methacrylic acid is 4.66 at $20^{\circ} \mathrm{C}$, but shifts to higher values upon incorporation in a PMAAchain. Values as disparate as $5.5^{[12]}$ and $7.3^{[13]}$ have been reported in different contributions and a theoretical study has estimated values in the 5.2-8.8 range as a function of molar mass, because of cooperativity effects. ${ }^{[14]}$ For a PMAA with a molecular mass of $50000 \mathrm{~g} \cdot \mathrm{mol}^{-1}$, full deprotonation was shown to occur at $\mathrm{pH}>7 .{ }^{[15]}$ By adding a large amount of $\mathrm{NaOH}$ after swelling with toluene, polymer dispersions at $\mathrm{pH} 13.6$ have been prepared. At this $\mathrm{pH}$ value, the carboxylic groups are fully deprotonated. The polymer-grafted TPP functions are not affected, because the ${ }^{31} \mathrm{P}$ NMR spectrum features a single resonance at the same chemical shift as for the swollen latex at natural $\mathrm{pH}(\delta-6.2),{ }^{[3]}$ stable in time. The ${ }^{1} \mathrm{H}$ NMR spectrum is also essentially identical to that observed at the natural $\mathrm{pH}$, both for the unswollen and tolueneswollen versions (Figure S3). We anticipated that deprotonation of the carboxylic acid functions would render the shell chains more hydrophilic, increasing their mobility by fully deploying them into the aqueous phase. At least, this is the reported behavior for PMAA homopolymer chains. ${ }^{[15]}$ However, the methacrylate monomer protons remain invisible, whether the latex is swollen with toluene of not, showing that the hydrophilic shell backbone maintains low mobility even at high $\mathrm{pH}$.

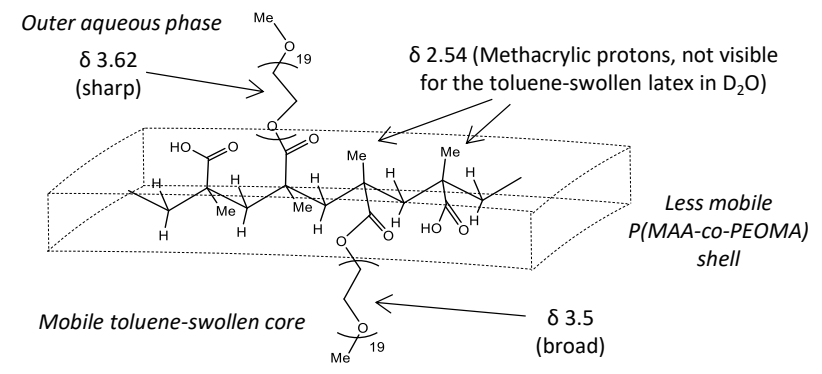

Figure 2. Cartoon of the proposed core-shell interphase structure for the toluene-swollen TPP@CCM latexes at the natural pH.

Another peculiar phenomenon can be appreciated by expanding the PEO proton resonance region, see Figure 3 for TPP@CCM-2 (the other latexes showed identical properties). Unlike the behavior at natural $\mathrm{pH}$ where the PEO methylene and methyl proton resonances are split into only two populations (Figure S2), a more complex shape is observed at $\mathrm{pH}$ 13.6. Two populations clearly correspond to those observed at natural $\mathrm{pH}$, both in chemical shift (though slightly upfield shifted) and linewidth and are given the same assignment: the sharper resonance (at $\delta$ 3.58 for the stronger methylene resonance, indicated as Lorentz1) is attributed to the PEO chains freely moving in the water phase and the broader one (centered at $\delta 3.40$ for the methylene resonance, Lorentz2) belongs to the mobile PEO chains located inside the swollen core. However, there is residual intensity in-between these two Lorentzian functions. A fit including a third Lorentzian function (Lorentz3) provides a better match with the experimental spectrum as shown in Figure 3, although not as good as that at natural $\mathrm{pH}$ (Figure S2). This third resonance is broad, indicating restricted mobility for the PEO protons belonging to this signal, hence inclusion in the swollen polymer core. The relative ratio of the three fractions (L1/L2/L3) is 27.1:39.4:33.5. Note that the estimated fraction for the water-solvated PEO chains $(27.1 \%)$ is close to that estimated at the natural $\mathrm{pH}(30.3 \%)$.

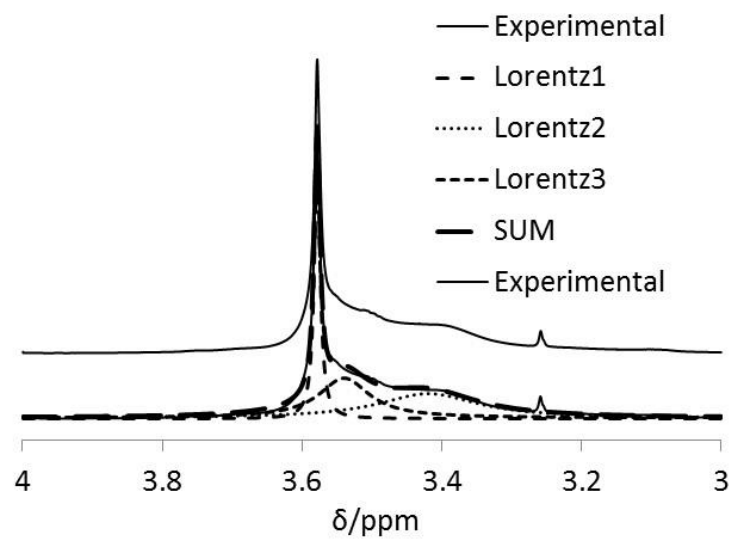

Figure 3. A: excerpt of the ${ }^{1} \mathrm{H}$ NMR spectra of the toluene-swollen TPP@CCM 2 at $\mathrm{pH} 13.6$ in the methylene and methoxy $\mathrm{PEO}$ proton resonance region and deconvolution of the $\mathrm{CH}_{2}$ resonance; the experimental spectrum is shown twice, above by itself and below superimposed with the fit as the sum of three Lorentzian functions.

It therefore appears that the MAA deprotonation does not change the core-shell interphase structuring. Since the core has low polarity, the deprotonated carboxylates that are placed inside the hydrophobic core will form tight ion pairs with sodium cations, the coordination of which is likely saturated by the PEO oxygen atoms of neighboring PEOMA monomer units, reminiscent of the alkali metal coordination by crown ethers. These Na-coordinated ethylene oxide functions are proposed to account for the third irregular Lorentzian distribution, the downfield shift relative to the free core-confined PEO chains being a consequence of the $\mathrm{Na}$ coordination, see Figure 4. The random arrangement of the carboxylates and PEO chains in the core accounts for the complex shape of this resonance. This study provides useful information for understanding the metal migration between the latex particles, which will be addressed below. 


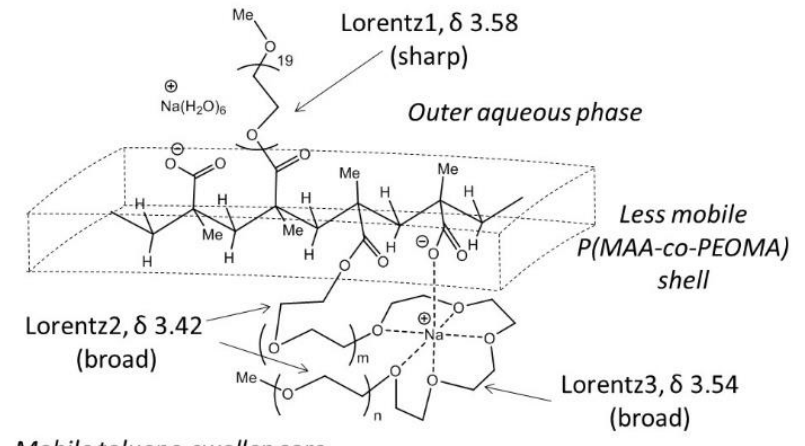

Mobile toluene-swollen core

Figure 4. Cartoon of the proposed core-shell interphase structure for the toluene-swollen TPP@CCM latex at pH 13.6.

\section{b) Interparticle metal migration.}

Loading TPP@CCM with complex $\left[\mathrm{Rh}(\mathrm{acac})(\mathrm{CO})_{2}\right]$ results in disappearance of the free TPP ${ }^{31} \mathrm{P}$ resonance at $\delta-6.6$ and appearance of a doublet at $\delta 47.5\left(\mathrm{~J}_{\mathrm{PRh}}=175 \mathrm{~Hz}\right)$, which is characteristic of the monophosphine adduct, see equation $1 .^{[3]}$ On the other hand, loading with only $1 / 2$ equivalent of metal complex yields silent spectra because the rate of the selfexchange process (equation 2) results in resonance coalescence at room temperature.

$$
\begin{aligned}
& {\left[\mathrm{Rh}(\mathrm{acac})(\mathrm{CO})_{2}\right]+\mathrm{TPP} @ \mathrm{CCM} \longrightarrow} \\
& {[\mathrm{Rh}(\mathrm{acac})(\mathrm{CO})(\mathrm{TPP} @ \mathrm{CCM})]+\mathrm{CO}} \\
& {[\mathrm{Rh}(\mathrm{acac})(\mathrm{CO})(\mathrm{TPP} @ \mathrm{CCM})]+\mathrm{TPP} @ \mathrm{CCM} \rightleftarrows} \\
& \text { TPP@CCM + }[\mathrm{Rh}(\mathrm{acac})(\mathrm{CO})(\mathrm{TPP} @ \mathrm{CCM})]
\end{aligned}
$$

This rapid intraparticle exchange phenomenon gives us the opportunity of monitoring the metal migration from one particle to another without having to differently label the filled and empty polymers. Mixing equimolar samples of fully $[\mathrm{Rh}(\mathrm{acac})(\mathrm{CO})]$ loaded and unloaded TPP@CCM should ideally show the resonances of both the coordinated and the free phosphine under the hypothesis of no metal migration, whereas full equilibration yields a silent spectrum. A fuller investigation of the NMR properties of the $[\mathrm{Rh}(\mathrm{acac})(\mathrm{CO})]$-loaded particles at various degrees of loading (Figure S4) shows residual resonances for the free phosphine functions up to $42 \%$ of metal loading and for the Rh-coordinated phosphine functions beyond $83.3 \%$ loading. When the experiment was run at the natural $\mathrm{pH}$ using TPP@CCM-2, a silent spectrum immediately resulted no matter how fast it was recorded after mixing, demonstrating very rapid metal redistribution among all polymer particles.

We can conceive three possible mechanisms for the interparticle metal migration: (I) metal dissociation and migration as a neutral molecular complex (e.g. an aqua adduct) through the aqueous phase; (ii) carboxylic acid assisted migration through shell-shell contact; (iii) direct phosphine exchange following corecore contact or interpenetration. An identical metal migration experiment run at higher $\mathrm{pH}$, where the particle outer shell is negatively charged, gave additional useful information. The time evolution of the ${ }^{31} \mathrm{P}\left\{{ }^{1} \mathrm{H}\right\}$ NMR spectrum is shown in Figure 5 . In this case, the resonances of $[\mathrm{Rh}(\mathrm{acac})(\mathrm{CO})(\mathrm{TPP} @ \mathrm{CCM})]$ at $\delta$ 47.5 and Rh-free TPP@CCM at $\delta-6.6$ are independently observable and their intensity decreases quite slowly, remaining detectable even after $11 \mathrm{~h}$ at room temperature. At the same time, a broad resonance without visible Rh coupling grows at $\delta 29.4$. Comparing with the results shown in Figure S4, we conclude that there are still nanoreactors with less than $50 \%$ of free phosphine functions and others with less than $25 \%$ of Rh-coordinated phosphine functions after $11 \mathrm{~h}$.

The interparticle Coulombic repulsion should slow down the metal migration process for both the core-core contact or transient interpenetration mechanism and for the carboxylic acid-assisted shell-shell contact mechanism, even though deprotonation is expected in principle to enhance the carboxylate binding power and favor Rh transfer to the outer shell. Migration as a molecular complex via the aqueous phase, on the other hand, should be $\mathrm{pH}$ insensitive or even favored if $\mathrm{OH}^{-}$coordinates $\mathrm{Rh}^{\prime}$ more strongly than water to yield a greater amount of the migrating molecular species, $[\mathrm{Rh}(\mathrm{acac})(\mathrm{OH})(\mathrm{CO})]$. This result is consistent with either the direct phosphine exchange mechanism through core-core contact or the carboxylate-assisted mechanism through shellshell contact and excludes the molecular migration through the continuous phase as the major migration pathway at natural $\mathrm{pH}$. It does not exclude, however, that the residual slow migration observed at high $\mathrm{pH}$ is associated to this pathway.

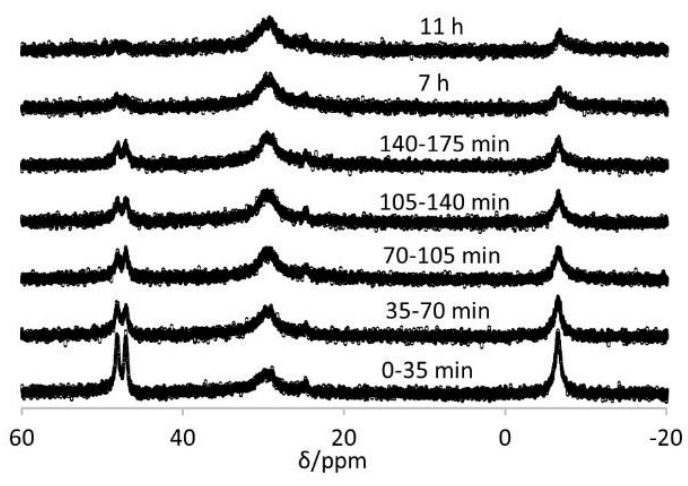

Figure 5. ${ }^{31} \mathrm{P}\left\{{ }^{1} \mathrm{H}\right\}$ NMR spectra of the latex obtained by mixing equimolar amounts of $[\mathrm{Rh}(\mathrm{acac})(\mathrm{CO})(\mathrm{TPP} @ \mathrm{CCM}-2)]$ and TPP@CCM-2 at $\mathrm{pH}$ 13.6. The data for each spectrum were collected for 35 minutes; the time intervals for data collection from the time of mixing are indicated on each spectrum.

\section{c) Migration of inorganic reagents to the hydrophobic polymer core.}

The identification of the species responsible for the new resonance at $\delta 29.4$ in Figure 5 and the reason for its formation only at high $\mathrm{pH}$ is a necessary step for the identification of the main metal migration pathway. The reaction stoichiometry and the absence of other major new resonances suggest that the product has a $P / R h$ ratio of 2 . The chemical shift of this resonance is typical of trans-[RhX(TPP) $\left.)_{2}(\mathrm{CO})\right]$ complexes (e.g. $\delta 28.97$ for $\mathrm{X}=$ $\mathrm{Cl}) .{ }^{16]}$ The main difference between the experiments carried out at high and natural $\mathrm{pH}$ is the excess $\mathrm{OH}^{-}$in the aqueous phase and deprotonated carboxylic acid functions on the polymer shell. 
The nucleophilicity of these functions could favor replacement of the acetylacetonate ligand. Since neither of these anions possesses strong tendency to saturate a second coordination site through either chelation (for methacrylato) or bridging (for both methacrylato and hydroxydo), binding of a second phosphine function becomes possible in the product.

In order to verify the compound stoichiometry, another experiment was carried out by loading TPP@CCM-3 with only $50 \%\left[\mathrm{Rh}(\mathrm{acac})(\mathrm{CO})_{2}\right]$, followed by increasing the $\mathrm{pH}$ to 13.6 by $\mathrm{NaOH}$ addition. The ${ }^{31} \mathrm{P}\left\{{ }^{1} \mathrm{H}\right\}$ spectrum of the resulting solution, shown in Figure $6 \mathrm{~A}(\mathrm{~b})$, confirms the formation of the same broad resonance at $\delta 29.4$. In this experiment the resonances of free and coordinated phosphine at $\delta-6.6$ and 47.5 were immediately unobservable, consistent with rapid metal migration at natural $\mathrm{pH}$.
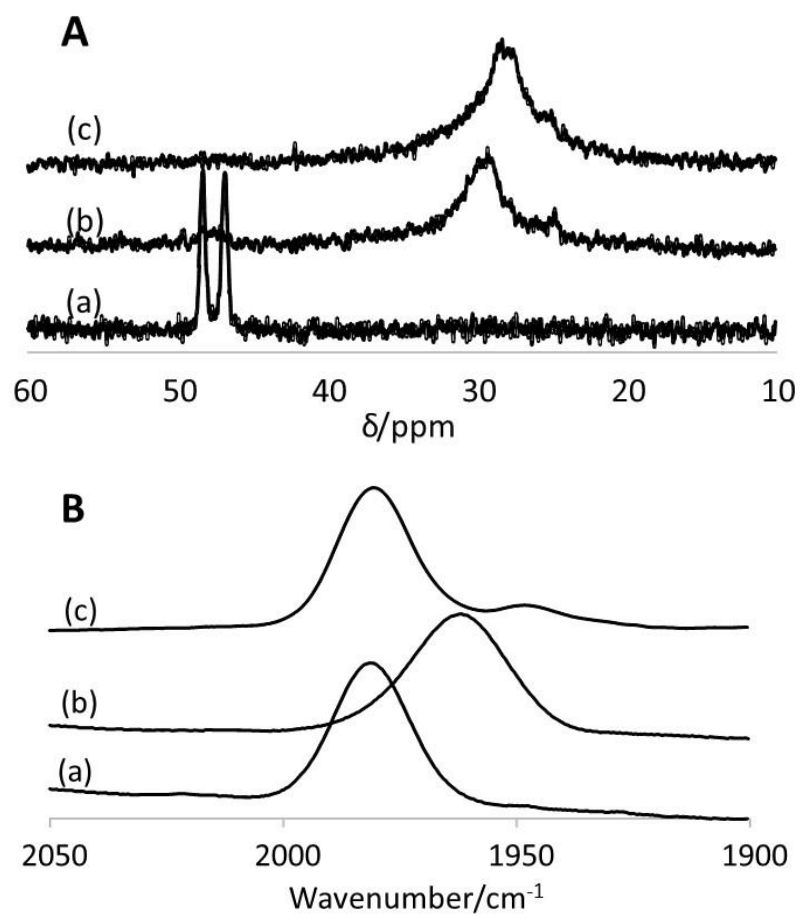

Figure 6. ${ }^{31} \mathrm{P}\left\{{ }^{1} \mathrm{H}\right\}$ NMR $(\mathrm{A})$ and IR (B) spectra of [Rh(acac)(CO)(TPP@CCM)]: (a) at $100 \%$ loading (natural $\mathrm{pH}$ ); (b) at $50 \%$ loading followed by addition of $\mathrm{NaOH}$ ( $\mathrm{pH} \mathrm{13.6);} \mathrm{(c)} \mathrm{at} 50 \%$ loading followed by the addition of $\mathrm{NaCl}$. Experiments (a) and (c) were run using TPP@CCM-2 ( $x=0.10$, or 30 TPP units per chain) and experiment (b) was run using TPP@CCM-3 ( $x=0.25$, or 75 TPP units per chain).

In order to learn more about the chemical nature of this species, the latex was investigated by IR spectroscopy. Molecular compounds with the stoichiometry $\left[\mathrm{RhX}(\mathrm{CO})(\mathrm{TPP})_{2}\right]$ are described in the literature for both $\mathrm{X}=\mathrm{OH}\left(\mathrm{v}_{\mathrm{CO}}=1961 \mathrm{~cm}^{-1} ; \delta\left({ }^{31} \mathrm{P}\right)\right.$ $=31.2)$ and $\mathrm{X}=\mathrm{O}_{2} \mathrm{CCH}_{3}\left(\mathrm{v}_{\mathrm{CO}}=1972 \mathrm{~cm}^{-1} ; \delta\left({ }^{31} \mathrm{P}\right)=34.4\right) \cdot{ }^{[17]}$ The latex resulting from the addition of $\mathrm{NaOH}$ to the $50 \%$ loaded [Rh(acac)(CO)(TPP@CCM-3)] shows a CO stretching vibration centered at $1962 \mathrm{~cm}^{-1}$, Figure $6 \mathrm{~B}(\mathrm{~b})$, which is in closer correspondence with the band of $\left[\mathrm{Rh}(\mathrm{OH})(\mathrm{CO})(\mathrm{TPP})_{2}\right]$. Formation of the methacrylato complex may be expected to be favored, given the suitable placement of the carboxylates, at least partially, in the inner core (see Figure 3). However, although the number of carboxylate functions (15 per chain) is sufficient for the metal stoichiometry of TPP@CCM-2 (30 phosphine groups per chain, i.e. $15 \mathrm{Rh}$ ions per chain), they are located only near the polymer shell, whereas the phosphine functions are homogeneously distributed in the polymer core. On the other hand, formation of the hydroxydo complexes implies migration of $\mathrm{NaOH}$ inside the hydrophobic core. This could occur through coordination of the $\mathrm{Na}$ ion by the PEO chains, as proposed for the $\mathrm{Na}$ counterion of the carboxylate groups in Figure 3.

In order to confirm that the new compound is $[\mathrm{Rh}(\mathrm{OH})(\mathrm{CO})$ $(\mathrm{TPP})_{2}$ ], resulting from incorporation of $\mathrm{NaOH}$ from the aqueous phase, we have also carried out a third experiment involving the same 50\% [Rh(acac)(CO)]-loaded TPP@CCM-2, but now NaCl was added to the aqueous solution at the same concentration used for $\mathrm{NaOH}$ in the previous experiment (details in the experimental section). The resulting latex gave the ${ }^{31} \mathrm{P}\left\{{ }^{1} \mathrm{H}\right\}$ NMR spectrum shown in Figure $6 \mathrm{~A}(\mathrm{c})$ and the IR spectrum shown in Figure $6 \mathrm{~B}(\mathrm{c})$. Although the $\mathrm{CO}$ stretching vibration (centered at $\left.1980 \mathrm{~cm}^{-1}\right)$ is coincidentally similar to that of [Rh(acac)(CO)(TPP@CCM-2)] (at $1981 \mathrm{~cm}^{-1}$, Figure 6B(a)), the ${ }^{31} \mathrm{P}\left\{{ }^{1} \mathrm{H}\right\}$ NMR resonance (centered at ca. $\delta 28.5$ ) is close to that attributed to $\left[\mathrm{Rh}(\mathrm{OH})(\mathrm{CO})(\mathrm{TPP} @ \mathrm{CCM}-2)_{2}\right]$, confirming that extensive formation of $\left[\mathrm{RhCl}(\mathrm{CO})(\mathrm{TPP} @ \mathrm{CCM}-2)_{2}\right]$ has taken place. For comparison, the molecular complex $\left[\mathrm{RhCl}(\mathrm{CO})(\mathrm{TPP})_{2}\right]$ shows a doublet at $\delta 28.97^{[16]}$ and a CO stretching vibration at $1978 \mathrm{~cm}^{-1}$ in benzene ${ }^{[18]}$ or at $1980 \mathrm{~cm}^{-1}$ in $\mathrm{CHCl}_{3} \cdot{ }^{[17 \mathrm{a}]}$ Conversely, adding $\mathrm{NaCl}$ to a [Rh(acac)(CO)(TPP@CCM-2)] latex (100\% Rh loading) gave no change in the ${ }^{31} \mathrm{P}$ NMR spectrum. These experiments illustrate that sodium chloride, like sodium hydroxide, is able to penetrate the CCM hydrophobic core. It further shows that, while neither $\mathrm{NaCl}$ nor $\mathrm{NaOH}$ react with $[\mathrm{Rh}(\mathrm{acac})(\mathrm{CO})$ (TPP@CCM)] (Equation 3), they do so in the presence of an additional equivalent of free TPP ligand (Equation 4). Note that the ${ }^{31} \mathrm{P}$ resonances of the $\left[\mathrm{RhX}(\mathrm{CO})(\mathrm{TPP} @ \mathrm{CCM}-2)_{2}\right]$ species $(\mathrm{X}$ $=\mathrm{OH}, \mathrm{Cl}$ ) in Figure 6A do not show Rh coupling. This is because the constrained location of the TPP ligands in the polymer core does not allow reaction completion: a fraction of the TPP@CCM ligands will be incapable of finding the unreacted $[\mathrm{Rh}(\mathrm{acac})(\mathrm{CO})$ (TPP@CCM)] partner but will be available to operate the associative exchange with the $\left[\mathrm{RhX}(\mathrm{CO})(\mathrm{TPP} @ \mathrm{CCM})_{2}\right]$ product, resulting in line broadening. The rate at which this reaction occurs (complete transformation at room temperature within the time needed to record the first IR spectrum after mixing) is quite remarkable, considering that it requires migration of ionic inorganic $\mathrm{Na}^{+} \mathrm{X}^{-}$species $(\mathrm{X}=\mathrm{OH}$ or $\mathrm{Cl})$, which are well solvated by water, toward a hydrophobic environment in which they are essentially insoluble.

$$
\begin{gathered}
{[\mathrm{Rh}(\mathrm{acac})(\mathrm{CO})(\mathrm{TPP} @ \mathrm{CCM})]+\mathrm{NaX} \longrightarrow} \\
\text { No reaction } \\
{[\mathrm{Rh}(\mathrm{acac})(\mathrm{CO})(\mathrm{TPP} @ \mathrm{CCM})]+\mathrm{NaX}+\mathrm{TPP} @ \mathrm{CCM} \longrightarrow} \\
{\left[\mathrm{RhX}(\mathrm{CO})(\mathrm{TPP} @ \mathrm{CCM})_{2}\right]+\mathrm{Na}(\mathrm{acac})} \\
(\mathrm{X}=\mathrm{OH}, \mathrm{Cl})
\end{gathered}
$$


We have also carried out the metal migration study using fully [Rh(acac)(CO)]-loaded and the Rh-free TPP@CCM-2 latexes in the presence of $\mathrm{NaCl}$ at the same concentration as the $\mathrm{NaOH}$ used for the experiment in Figure 5, i.e. at the same ionic strength. The result of this experiment is the immediate generation of a solution showing an NMR spectrum identical to that in Figure $6 \mathrm{~A}(\mathrm{c})$. This result confirms that the rate of metal migration is controlled by the particle-particle contact and/or transient interpenetration, which may occur for the latex at natural $\mathrm{pH}$, either with or without addition of $\mathrm{NaCl}$, whereas it is strongly retarded upon deprotonation by $\mathrm{NaOH}$ of the polymer shell carboxylic acid functions.

\section{d) Shell-shell or core-core contact?}

The dramatically reduced rate of metal migration for the negatively charged polymer particles relative to the neutral ones confirms the need for particle-particle contact but does not distinguish the direct phosphine exchange though core-core contact and the carboxylic acid-assisted exchange through shellshell contact. A distinction of these two mechanisms can be made on the basis of dynamic light scattering studies, using the reactions indicated in equation 4 as probes. Indeed, in the absence of core-core contact/interpenetration, the two phosphine ligands needed to coordinate a given $\mathrm{Rh}$ center must necessarily be placed within the same polymer core. In case of core-core contact/interpenetration, on the other hand, a certain extent of particle-particle coupling is expected.

As shown in Figure $7 \mathrm{a}$, mixing equivalent amounts of TPP@CCM-3 (0\% Rh, A) and [Rh(acac)(CO)(TPP@CCM-3)] $(100 \% \mathrm{Rh}, \mathrm{B})$ yields a dispersion where the particle size distribution remains essentially unchanged. This is because, even at $50 \%$ loading, the Rh coordination sphere does not allow a second phosphine ligand to coordinate in the absence of the $\mathrm{NaX}$ $(\mathrm{X}=\mathrm{OH}, \mathrm{Cl})$ reagent and coupling cannot occur, even in the presence of interpenetration. When the samples $A$ and $B$ are treated with $\mathrm{NaOH}$ to raise their $\mathrm{pH}$ to 13.6 , the size distribution does not significantly change relative to natural $\mathrm{pH}$, see Figure $7 \mathrm{~b}$. Mixing together $\mathrm{A}$ and $\mathrm{B}$ after individually raising their $\mathrm{pH}$ does not result in any significant change in the size distribution, as expected because of the slow metal migration (Figure 5). However, when the $\mathrm{pH}$ is raised only after mixing $\mathrm{A}$ and $\mathrm{B}$, i.e. when the $\mathrm{Rh}$ distribution is equilibrated at $50 \%$ loading in all particles as we know from the NMR study, the size distribution shifts significantly to higher average size values. This demonstrates that the reaction leading to $[\mathrm{Rh}(\mathrm{OH})(\mathrm{CO})$ (TPP@CCM-3) 2 ] may also involve, for a fraction of the Rh centers, two phosphine ligands belonging to two different particles. This fraction cannot be very extensive, however, otherwise macrogelation and precipitation of the latex would occur. Incidentally, this result also shows that reaction 4 (for $X=O H$ ) is kinetically competitive with the deprotonation of the shell carboxylic functions. If deprotonation were much faster than reaction 4, the negative charge accumulation on the polymer particle surface would lead to rapid particle separation, therefore not allowing any coupling to occur. The same aggregation phenomenon occurs upon mixing samples $A$ and $B$ pretreated with $\mathrm{NaCl}$ (same ionic strength as the experiment with $\mathrm{NaOH}$ ), see Figure 7c. In this case, the presence of $\mathrm{NaCl}$ in the aqueous phase before mixing has no effect on the metal exchange, since the particle shell remains neutral and interpenetration is not blocked. The intervention of core-core contact/interpenetration for the TPP@CCM latex is therefore confirmed, proving that direct phosphine exchange constitutes the major mechanism for interparticle metal migration at the natural $\mathrm{pH}$.

A few additional considerations are in order. The size distribution $\left(D_{z}=\right.$ ca. $70 \mathrm{~nm}$ for TPP@CCM-3, whether $[\mathrm{Rh}(\mathrm{acac})(\mathrm{CO})]$-loaded or not, whether at natural or basic $\mathrm{pH}$ ) shifts by approximately the same extent upon addition of $\mathrm{NaOH}$ (Figure $7 \mathrm{~b}, \mathrm{D}_{\mathrm{z}}=93 \mathrm{~nm}$ ) and $\mathrm{NaCl}$ (Figure $7 \mathrm{c}, \mathrm{D}_{\mathrm{z}}=94 \mathrm{~nm}$ ). This suggests that, for the $\mathrm{NaOH}$ reaction, coupling must actually be faster than shell deprotonation. A carboxylic acid deprotonation is a relatively rapid but not instantaneous process (for instance, activation barriers as low as $13.5 \mathrm{kcal} / \mathrm{mol}$ have been reported for the deprotonation of $\mathrm{CF}_{3} \mathrm{COOH}$ on a silver surface ${ }^{[19]}$ or in the 20 $25 \mathrm{kcal} / \mathrm{mol}$ range for various acids on a copper surface ${ }^{[20]}$, although the build-up of negative charge has probably a negative effect on the deprotonation kinetics of adjacent acidic functions in a polymer chain. Thus, $\mathrm{NaOH}$ migration into the polymer core is significant before the negative charge build-up on the particle shell becomes sufficient to suppress the particle interpenetration process. These observations suggest that the $\mathrm{Na}^{+} X^{-}$migration to the polymer core is an extremely rapid and facile process, which
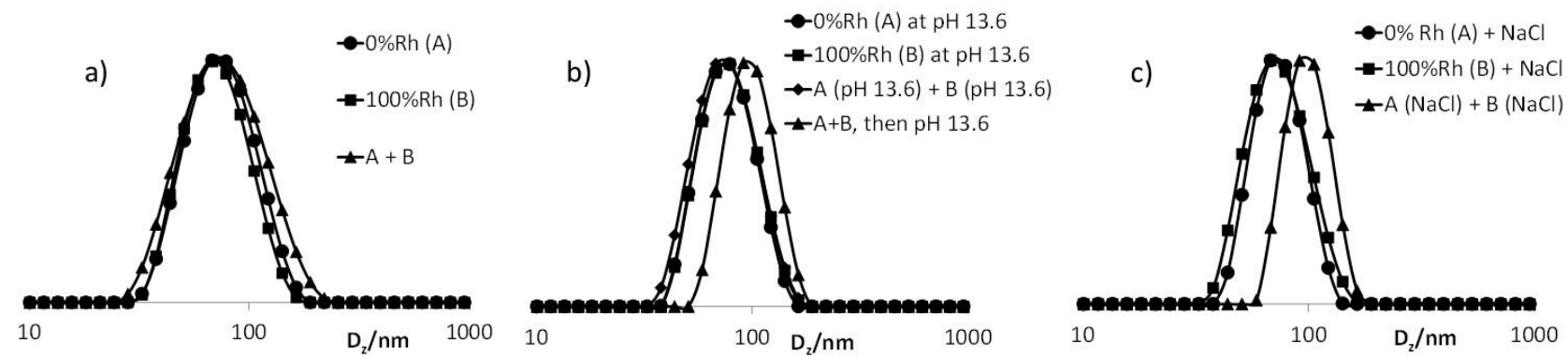

Figure 7. DLS monitoring of various reactions between TPP@CCM-3 (sample A, 0\% Rh) and $[R h(a c a c)(C O)(T P P @ C C M-3)]$ (sample B, 100\% Rh). a) At natural $\mathrm{pH}\left(\mathrm{A}: \mathrm{D}_{\mathrm{z}}=70 \mathrm{~nm} ; \mathrm{PDI}=0.10 . \mathrm{B}: \mathrm{D}_{\mathrm{z}}=67 \mathrm{~nm} ; \mathrm{PDI}=0.12 . \mathrm{A}+\mathrm{B}: \mathrm{D}_{\mathrm{z}}=74 \mathrm{~nm} ; \mathrm{PDI}=0.22\right)$ b) At pH $13.6\left(\mathrm{~A}: \mathrm{D}_{z}=72 \mathrm{~nm} ; \mathrm{PDI}=0.09 . \mathrm{B}: \mathrm{D}_{z}=74 \mathrm{~nm} ; \mathrm{PDI}=0.14 . \mathrm{A}\right.$ $\left(\mathrm{pH}\right.$ 13.6) $+\mathrm{B}\left(\mathrm{pH}\right.$ 13.6): $\mathrm{D}_{\mathrm{z}}=77 \mathrm{~nm} ; \mathrm{PDI}=0.21 . \mathrm{A}+\mathrm{B}$, then $\left.\left.\mathrm{pH} 13.6: \mathrm{D}_{\mathrm{z}}=93 \mathrm{~nm} ; \mathrm{PDI}=0.09\right) . \mathrm{c}\right)$ At natural $\mathrm{pH}$ with $[\mathrm{NaCl}]=0.37 \mathrm{M}\left(\mathrm{A}: \mathrm{D}_{\mathrm{z}}=69 \mathrm{~nm} ; \mathrm{PDI}=0.17 . \mathrm{B}\right.$ : $\mathrm{D}_{z}=76 \mathrm{~nm} ; \mathrm{PDI}=0.24$. A+B: $\left.\mathrm{D}_{\mathrm{z}}=94 \mathrm{~nm} ; \mathrm{PDI}=0.07\right)$. 
seems surprising in light of the much greater compatibility of $\mathrm{Na}^{+} \mathrm{X}^{-}$with water relative to toluene. This point will be addressed again in the next section.

Another interesting observation concerns the size and the size distribution of the coupled particles after reaction with $\mathrm{NaOH}$ or $\mathrm{NaCl}$. Assuming spherical shape for the coupled objects, an increase of $D_{z}$ from 70 to $94 \mathrm{~nm}$ corresponds to a volume ratio of ca. 2.4, suggesting that the agglomerated particles include on average 2-3 original particles. On the other hand, the distribution remains narrow and shifts completely, namely no particles remain at the low-size tail of the distribution before reaction, showing that essentially all particles have become involved in a coupling process. Why would all particles be coupled but then agglomeration stops at the level of 2-3 particles per aggregate without further evolution? A possible explanation could be that the decrease of the total particle surface area corresponding to this agglomeration leads to an optimum of stability provided by the hydrophilic shells. However, an alternative explanation can also be imagined by extending the collision theory of chemical reactions to the particle-particle collisions leading to interpenetration. The collision of two particles is more probable than the simultaneous collision of three or more particles, by the same principle that bimolecular elementary processes are more probable than termolecular ones in chemical reactions.

At any time, the aqueous dispersion will contain a particle distribution comprising a majority of individual particles and a small fraction of interpenetrated agglomerates of essentially only two particles. The chemical reaction can occur on both types of objects, leading to intraparticle (for both individual and already coupled objects) or interparticle (only for the agglomerates, leading to coupling) formation of $\left[\mathrm{RhX}(\mathrm{TPP})_{2}(\mathrm{CO})\right](\mathrm{X}=\mathrm{OH}$ or $\mathrm{Cl})$ complexes. The supplemental Figure $\mathrm{S} 5$ shows a pictorial view of this process. The probability of interparticle coupling vs. intraparticle reaction is proportional to the fraction of associated particles times the extent of interpenetration (fraction of free phosphine ligands located in the interpenetrated area of the associated particles). Residual individual particles at the end of the chemical reaction can only be present if this probability is very small. Since Figure 7 shows that essentially no original nanoreactor remains uncoupled, this probability appears as sufficiently high. For the TPP@CCM-3 sample used for these experiments, there are ca. 2100 cross-linked arms per particle and 75 TPP ligands per chain for a total of $1.6 \cdot 10^{5}$ TPP ligands and $0.8 \cdot 10^{5} \mathrm{Rh}$ complexes per particle. Thus, the persistence of an individual particle at the end of the chemical reaction requires 80000 intraparticle chemical reactions without anyone of them involving a coupling event. Conversely, the formation of larger particle aggregates requires further collisions of an already coupled two-particle object and a third object (individual particle or already coupled aggregate). While the probability of individual particle collisions scales with the square of the particle concentration, the probability that a coupled two-particle aggregate collides with another individual particle scales linearly with the concentration of each entity and will thus be very small at the beginning of the reaction when most of the TPP and [Rh(acac)(CO)(TPP@CCM)] functions have not yet reacted. Clearly, as the reaction progresses and the concentration of the coupled objects increases, the collision probability leading to much greater aggregates increases but at the same time the fraction of unreacted free TPP and [Rh(acac)(CO)(TPP@CCM)] functions has decreased. Thus, these collisions are less and less likely to lead to further coupling.

\section{e) DLS study of the slow metal migration at $\mathrm{pH} \mathbf{1 3 . 6}$}

The slow metal migration at $\mathrm{pH} 13.6$ (section b, Figure 5) proves that the dominant pathway of interparticle metal migration involves particle-particle contact. The DLS study presented in the previous section (Figure 7) further demonstrates that this contact must involve core-core interpenetration. However, one question still remains unanswered: does metal migration as molecular species through the continuous aqueous phase occur at all? Notably, does the residual slow metal migration at $\mathrm{pH} 13.6$ result from the interpenetration pathway following a less favorable particle-particle contact or from an additional pathway involving metal dissociation from the polymer scaffold and migration as a molecular species through the aqueous phase?

A DLS investigation of the particle size after complete exchange at $\mathrm{pH} 13.6$ provides useful information. Should migration still involve core-core contact, coupled particles would be observed. If, on the other hand, core-core contact is completely shut down, no coupling process would result from the molecular migration and/or the shell-shell contact mechanisms. The DLS investigation, shown in Figure 8, unequivocally shows that the average particle size and size distribution do not change. Hence, this experiment demonstrates that the slow migration at $\mathrm{pH} 13.6$ occurs without core-core contact.

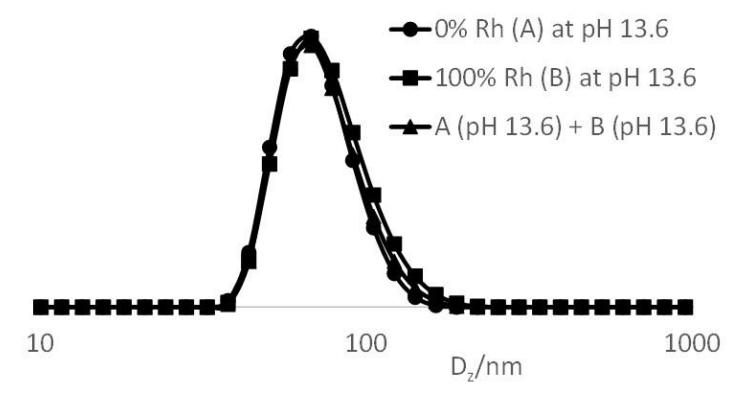

Figure 8. DLS study of the metal migration at pH 13.6 using TPP@CCM-3 Sample A, 0\% Rh $\left(D_{z}=76.1 \mathrm{~nm} ; \mathrm{PDI}=0.11\right)$; sample $B, 100 \% R h\left(D_{z}=87.9\right.$ $\mathrm{nm} ; \mathrm{PDI}=0.19)$; the $\mathrm{DLS}$ of the $1: 1 \mathrm{~A}+\mathrm{B}$ mixture $\left(\mathrm{D}_{z}=82.2 \mathrm{~nm} ; \mathrm{PDI}=0.15\right)$ was recorded after completion of the metal migration according to ${ }^{31} \mathrm{P}$ NMR monitoring $(160 \mathrm{~h})$.

It is not possible at the moment to unequivocally distinguish between the carboxylate-assisted associative exchange through shell-shell contact and the molecular migration through the continuous phase at high $\mathrm{pH}$. The Coulombic repulsion introduced by the charged carboxylate functions certainly disfavors shell-shell contact. However, this contact suffers from a weaker electrostatic barrier than core-core interpenetration. One possible way to distinguish these two pathways would be to investigate the metal migration for a related polymeric 
nanoreactor where the carboxylate functions are replaced by less coordinating anions. This is within our plans of future synthetic and mechanistic studies. It can be affirmed, however, that both the carboxylate exchange mechanism through shell-shell contact and the molecular migration mechanism through the continuous phase should be favored at high $\mathrm{pH}$, the former because anionic carboxylates are stronger ligands than the neutral conjugate acid and the latter because hydroxide is a stronger ligand than water. Therefore, being already rather inefficient at high $\mathrm{pH}$, these mechanisms should contribute even less to the overall metal migration process at the natural $\mathrm{pH}$.

\section{f) Investigation of a model molecular reaction}

The molecular version of equation 4 has not been previously reported in the literature. Therefore, we have proceeded to its independent investigation. The molecular equivalents of equations 3 and 4 are represented below in equations 5 and 6 , the $[\mathrm{Rh}(\mathrm{acac})(\mathrm{CO})(\mathrm{TPP})]$ complex being generated in situ from $\left[\mathrm{Rh}(\mathrm{acac})(\mathrm{CO})_{2}\right]$ and TPP.

$$
\begin{aligned}
& {\left[\mathrm{Rh}(\mathrm{acac})(\mathrm{CO})_{2}\right] \underset{-\mathrm{CO}}{\stackrel{\mathrm{TPP}}{\longrightarrow}}[\mathrm{Rh}(\mathrm{acac})(\mathrm{CO})(\mathrm{TPP})]} \\
& \stackrel{\mathrm{X}^{-}}{\longrightarrow} \text { No further reaction }
\end{aligned}
$$

$$
\left[\mathrm{Rh}(\mathrm{acac})(\mathrm{CO})_{2}\right] \underset{-\mathrm{CO}, \text {-acac }^{-}}{\stackrel{2 \mathrm{TPP}, \mathrm{X}^{-}}{\longrightarrow}}\left[\mathrm{RhX}(\mathrm{CO})(\mathrm{TPP})_{2}\right]
$$

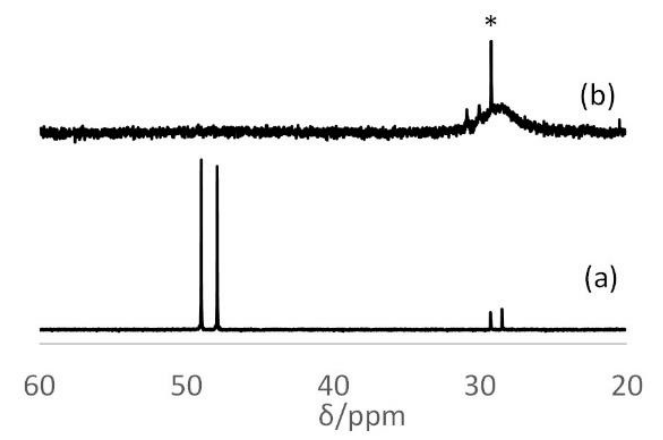

Figure 9. ${ }^{31} \mathrm{P}$ NMR spectra of the product of the reaction between $\left[\mathrm{Rh}(\mathrm{acac})(\mathrm{CO})_{2}\right]$ and TPP in the presence of 1 equiv of $n \mathrm{Bu} 4 \mathrm{NCl}$ in toluene. (a) $\mathrm{P} / \mathrm{Rh}=1.06$. (b) $\mathrm{P} / \mathrm{Rh}>2$. The starred resonance $(\delta 29.25)$ corresponds to a minor amount of phosphine oxide impurity.

Indeed, the reaction is rapid and quantitative when carried out in toluene using $n \mathrm{Bu} 4 \mathrm{NCl}$ as reagent. Under these conditions, use of slightly more than one equivalent of TPP $(6 \%)$ gave rise to the dominant ${ }^{31} \mathrm{P}$ NMR signal of $[\mathrm{Rh}(\mathrm{acac})(\mathrm{CO})(\mathrm{TPP})]$ at $\delta 48.44\left(\mathrm{~J}_{\mathrm{PRh}}\right.$ $=175.3 \mathrm{~Hz})$ and a minor doublet at $\delta 28.90\left(\mathrm{~J}_{\mathrm{PRh}}=126.8 \mathrm{~Hz}\right)$ for $\left[\mathrm{RhCl}(\mathrm{CO})(\mathrm{TPP})_{2}\right]$ (Figure 9a). Use of a larger (but still lower than 2 equivalents) TPP amount gave a more intense higher field resonance and a smaller lower field one. Raising the $\mathrm{P} / \mathrm{Rh}$ ratio to slightly more than 2 equivalents made the [Rh(acac)(CO)(TPP)] resonance completely disappear and yielded a broad signal without $\mathrm{Rh}$ coupling for $\left[\mathrm{RhCl}(\mathrm{CO})(\mathrm{TPP})_{2}\right]$ because of self- exchange (Figure 9b). Incidentally, this result confirms that the large linewidth of the $\left[\mathrm{RhCl}(\mathrm{CO})(\mathrm{TPP} @ \mathrm{CCM})_{2}\right]$ resonance in Figure $6 \mathrm{~A}$ results from incomplete TPP consumption. The total consumption of the $[\mathrm{Rh}(\mathrm{acac})(\mathrm{CO})(\mathrm{TPP})]$ intermediate is confirmed by the complete disappearance of the acetylacetonate resonances from the ${ }^{1} \mathrm{H}$ NMR spectrum at $\delta 5.34$ (methyne proton) and 2.74 (methyl protons), but no new resonances were detected for the free acac anion since the resulting sodium salt is insoluble in the NMR solvent $\left(\mathrm{CDCl}_{3}\right)$.

We have then proceeded to investigate the reaction in a biphasic toluene/water medium in order to simulate the process occurring inside the nanoreactor core. The extent of the reaction was evaluated with a chemically inert phosphine sulfide as internal standard (see experimental section). Mixing the [Rh(acac)(CO)(TPP)]-TPP (1 equiv) toluene solution with aqueous $\mathrm{NaX}(\mathrm{X}=\mathrm{OH}, \mathrm{Cl})$ resulted only in a slow interfacial reaction, as expected from the total insolubility of the sodium salts in toluene and of the Rh complex in water. Even after $1 \mathrm{~h}$ of stirring at room temperature, the ${ }^{31} \mathrm{P}$ NMR spectra revealed only a minor broad resonance for the expected $\left[\mathrm{RhX}(\mathrm{CO})(\mathrm{TPP})_{2}\right]$ products, see Figure 10(a). All P-containing compounds completely partition in favor of the toluene phase. Even though the resonance integration is subject to a large uncertainty, it seems that the reaction with $\mathrm{NaCl}$ proceeds a bit faster than with $\mathrm{NaOH}$, the estimated conversion after $1 \mathrm{~h}$ being ca. $8 \%$ for $\mathrm{NaOH}$ and ca. $13 \%$ for $\mathrm{NaCl}$. Next, both reactions were repeated in the presence of excess $\mathrm{PEO}_{1000}(\mathrm{EO} / \mathrm{Rh}$ ratio $=6.5)$. The polymer molar mass (22 EO units on average) and the amount used relative to $\mathrm{Rh}$ approximately correspond to those of the related experiment with TPP@CCM. The reactions were again very slow, Figure 10(b), although the estimated conversions after $1 \mathrm{~h}$ are a bit greater than in the experiment without additive (ca. $16 \%$ for $\mathrm{NaOH}$ and ca. $20 \%$ for $\mathrm{NaCl}$ after $1 \mathrm{~h}$ ). Thus, PEO plays a poor vectorizing role to bring $\mathrm{NaX}$ to the toluene phase. This result is not unexpected because $\mathrm{PEO}_{1000}$, although also soluble in toluene, partitions essentially quantitatively in favor of the aqueous phase when placed in a water/toluene biphasic system. ${ }^{[11]}$

We have also tested the vectorization properties of 18-crown6 , which is well known for its ability to bring inorganic anions into organic solutions, for the same reactions. Since this crown ether has the best size compatibility with potassium, these experiments were carried out with $\mathrm{KOH}$ and $\mathrm{KCl}$ as reagents. Using a stoichiometric amount of 18 -crown-6 relative to potassium led again to a very slow reaction with $\mathrm{KOH}$ and to qualitatively similar spectra to those shown for the $\mathrm{NaOH} / \mathrm{PEO}_{1000}$ reaction (estimated conversions: ca. $16 \%$ after $1 \mathrm{~h}$ ). However, use of a larger amount $([18-c r o w n-6] /[\mathrm{K}]=5)$ led to a fast reaction with nearly quantitative conversion after only $10 \mathrm{~min}$, see Figure $10 \mathrm{~A}(\mathrm{c})$. The relatively small but non zero amount of residual free TPP is indicated by the relatively sharp resonances of both the $\left[\mathrm{Rh}(\mathrm{OH})(\mathrm{CO})(\mathrm{TPP})_{2}\right]$ product and the residual $[\mathrm{Rh}(\mathrm{acac})(\mathrm{CO})(\mathrm{TPP})]$ intermediate (small doublet resonance centered at ca. $\delta 49.5$, visible in the expanded trace). The dramatic acceleration by the excess 18crown-6 probably results from the profound alteration of the solvent medium (1.4 mL of the crown ether for $2 \mathrm{~mL}$ of water), partially compatibilizing the two phases. Use of 18-crown-6 in combination with $\mathrm{KCl}$, on the other hand, results in a fast and 
quantitative reaction after $10 \mathrm{~min}$ even when using a stoichiometric amount, see Figure $10 \mathrm{~B}(\mathrm{c})$. The total conversion (complete consumption of TPP) is indicated by the very sharp resonances of the two $\mathrm{Rh}$ compounds, the $\left[\mathrm{RhCl}(\mathrm{CO})(\mathrm{TPP})_{2}\right]$ product at $\delta 29.55\left(\mathrm{~J}_{\mathrm{PRh}}=128.8 \mathrm{~Hz}\right)$ and the residual $[\mathrm{Rh}(\mathrm{acac})$ (CO)(TPP)] intermediate at $\delta 49.43\left(\mathrm{~J}_{\mathrm{PRh}}=177.9 \mathrm{~Hz}\right)$. The intermediate persists because the amount of TPP used in the experiment was slightly less than 2 equiv per Rh. Comparison of Figure $10 \mathrm{~A}$ and Figure $10 \mathrm{~B}$ shows that the reaction is in each case more extensive/faster for $\mathrm{X}=\mathrm{Cl}$ relative to $\mathrm{X}=\mathrm{OH}$ under the same experimental conditions, particularly for the experiments with the crown ether (c). This difference may result from the weaker $\mathrm{H}$ bonding interactions established by $\mathrm{Cl}^{-}$relative to $\mathrm{OH}^{-}$with water, hence its greater propensity to be transferred to the organic phase.
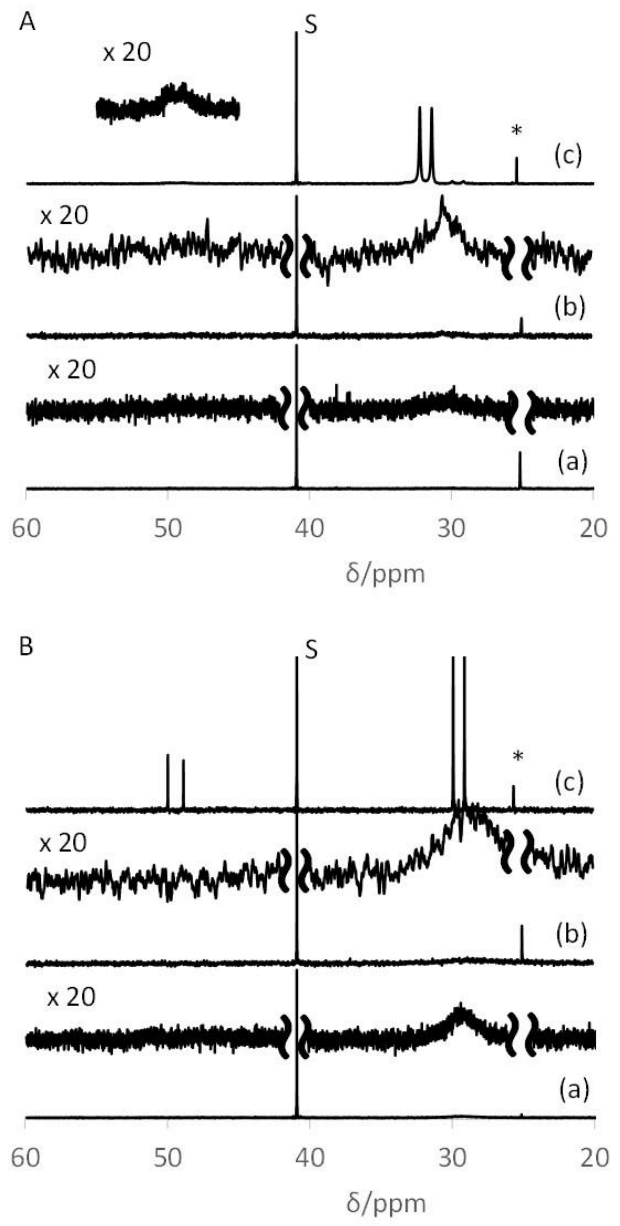

Figure 10. ${ }^{31} \mathrm{P}$ NMR spectra of the organic phase resulting from the biphasic reaction between $[\mathrm{Rh}(\mathrm{acac})(\mathrm{CO})(\mathrm{TPP})]-T P P$ in toluene and $\mathrm{M}^{+} \mathrm{X}^{-}$in water $(\mathrm{X} / \mathrm{Rh}$ = ca. 13) under various conditions. $\mathrm{A}: \mathrm{X}=\mathrm{OH} ; \mathrm{B}: \mathrm{X}=\mathrm{Cl}$. (a) With $\mathrm{NaX}$, no additional additives, $t=1 \mathrm{~h}$. (b) With $\mathrm{NaX}+\mathrm{PEO}_{1000}, \mathrm{t}=1 \mathrm{~h}$. (c) With $\mathrm{KX}+18$ crown $-6, t=10 \mathrm{~min}$. See text for the relative amounts of the reagents. The resonance marked with $\mathrm{S}$ belongs to the internal standard (see experimental section; TPP/S = 20.5:1) and the starred resonance is the TPP oxide impurity.

We remind that, on the other hand, the reactions carried out in the presence of TPP@CCM, for both $\mathrm{NaOH}$ and $\mathrm{NaCl}$, are quantitative and immediate, as most strikingly shown by the complete interparticle coupling (Figure 7), even for $\mathrm{NaOH}$ where the reaction inside the particle core is faster than the shell carboxylic acid deprotonation. The toluene and water phases are well separated by the CCM shell. Hence, the nature and structuring of the core-shell interface, discussed above in section a (Figure 2), seems crucial for allowing the rapid diffusion of $\mathrm{NaX}$ to the polymer core. The lack of shell backbone solvation by either water or toluene for the toluene-swollen particles induces a less mobile interface and forces a random distribution of the PEO chains both inside the polymer core and in the continuous aqueous phase, overruling the natural thermodynamic preference of free PEO chains to be located quantitatively in water. Although the backbone mobility on the NMR time scale is insufficient to observe a sufficiently sharp methacrylic methyl proton resonance, it must still be sufficient to rapidly exchange the inner and outer PEO chains (but no so rapidly to induce coalescence in the NMR). This exchange must obviously drag $\mathrm{NaX}$ molecules inside the hydrophobic core through $\mathrm{Na}^{+}$coordination by the PEO chains, as proposed for the interface structure at high $\mathrm{pH}$ (Figure 3). Once inside the polymer core, the naked $\mathrm{X}^{-}$ions are able to rapidly attack the Rh centers leading to expulsion of the acetylacetonate anions.

\section{Conclusions}

We have reported and analyzed here two previously undescribed phenomena concerning unimolecular core-shell polymers in stable aqueous dispersions. The core-shell structure of the polymers in question (TPP@CCM) was generated using amphiphilic diblock arms cross-linked at the very end of the hydrophobic segment, with anchored ligands in the hydrophobic core outside the cross-linked part. The first phenomenon is interparticle molecular migration, revealed by the use of rhodium complexes as the migrating molecules and polymer-anchored phosphine functions as NMR spectroscopic probes. Fast migration of organic molecules between the polymer core and an outer continuous organic phase had already been demonstrated through the efficiency of the CCM as catalytic nanoreactors in biphasic hydroformylation, ${ }^{[3-5]}$ where the reaction rate was shown to be affected only to a minor extent by the reactant and product mass transport kinetics. We have now demonstrated that molecular migration from one polymer core to another is very rapid, mostly occurring through direct contact between the particle cores during collisions. Interparticle metal migration as a molecular complex through the aqueous phase and/or carboxylate exchange through shell-shell contact, however, appears responsible for the residual slow migration at high $\mathrm{pH}$. The second unprecedented phenomenon is the rapid transport of water confined ionic compounds to the hydrophobic particle core, in which they are totally insoluble, revealed by a peculiar, unprecedented reaction with the core-contained $\mathrm{Rh}$ complexes that induces the coordination of two phosphine ligands per Rh atom. These reactions occur mostly within a single particle core, but occasional interparticle coupling reactions also occur during collisions, as clearly demonstrated by the DLS experiments on the $50 \%\left[\mathrm{Rh}(\mathrm{acac})(\mathrm{CO})_{2}\right]$-loaded samples upon treatment with $\mathrm{NaOH}$ 
or $\mathrm{NaCl}$. Our previously reported catalytic studies have also given evidence that the activated catalyst may, under vigorous stirring and forcing conditions, lead to interparticle coupling, a phenomenon that is apparently correlated to metal leaching. ${ }^{[4]}$ The knowledge acquired with the investigations reported here will help further optimize the macromolecular structure aiming at achieving the zero leaching target in catalytic applications. The remarkable ability of simple $\mathrm{Na}^{+} X^{-}(X=\mathrm{OH}, \mathrm{Cl})$ inorganic compounds to penetrate the toluene-swollen hydrophobic nanoreactor core seems determined by the structuring of the polymer core-shell interface, which forces a fraction of the PEO chains to be confined in the polymer core, although the backbone restricted mobility still allows sufficiently fast exchange of the inner and outer PEO chains. The peculiar action of the core-shell interface structuring, vectorizing ionic compounds from their preferred aqueous phase toward the hydrophobic one in which they are much less compatible, is relevant to anion transport across biological membranes and also opens many interesting perspectives for catalytic applications to reactions involving ionic compounds as co-catalysts or stoichiometric reagents.

\section{Experimental Section}

General. All manipulations were performed under an inert atmosphere of dry argon by using Schlenk line techniques. Solvents were dried by standard procedures and distilled under argon prior to use. Acetylacetonatodicarbonyl rhodium(I) ([Rh(acac) $\left.(\mathrm{CO})_{2}\right], 99 \%$, Strem), triphenylphosphine (TPP, >98.5\%, Fluka), PEO1000 (Alfa Aesar) and 18crown-6 $(99 \%$, Janssen chimica) were used as received. Deuterated solvents $\left(\mathrm{D}_{2} \mathrm{O}, \mathrm{CDCl}_{3}, \mathrm{C}_{6} \mathrm{D}_{5} \mathrm{CD}_{3}\right.$, THF- $\mathrm{D}_{8}$ ) were purchased from Eurisotop. Latexes of core cross-linked nanoparticles functionalized by triphenylphosphine (TPP@CCM) were prepared as recently described. ${ }^{\left[{ }^{3]}\right.}$ The characteristics of the used latexes are summarized in Table 1.

Characterization techniques. NMR: ${ }^{1} \mathrm{H}$ NMR and ${ }^{31} \mathrm{P}$ NMR spectra were recorded in $5 \mathrm{~mm}$ diameter tubes at $297 \mathrm{~K}$ in $\mathrm{D}_{2} \mathrm{O}$ using a Bruker Avance 400 spectrometer. ${ }^{1} \mathrm{H}$ chemical shifts were determined using the residual peak of deuterated solvent as internal standard and are reported in ppm (ס) relative to tetramethylsilane. ${ }^{31} \mathrm{P}$ chemical shifts are reported relative to external $85 \% \mathrm{H}_{3} \mathrm{PO}_{4}$. Peaks are labelled as singlet (s), doublet (d), triplet $(\mathrm{t})$, multiplet $(\mathrm{m})$ and broad (br). For the CCM characterization, the chemical shift scale was calibrated on the basis of the solvent peak $(\delta 2.50$ for DMSO, 4.79 for $\mathrm{D}_{2} \mathrm{O}$ ), and 1,3,5-trioxane was used as an integration reference $(\delta 5.20)$.

FTIR: Infrared spectra on the colloidal dispersions were measured with an FTIR 6700 ThermoScientific spectrometer equipped with DLaTGS detector. All spectra were collected in the transmission mode using a sealed cell equipped with $\mathrm{CaF}_{2}$ windows with 20 scans and a nominal resolution of $4 \mathrm{~cm}^{-1}$.

$D L S:$ The intensity-average diameters of the latex particles $\left(D_{z}\right)$ and the polydispersity index (PDI) were measured at $25^{\circ} \mathrm{C}$ on a Malvern Zetasizer NanoZS. After filtration through a $0.45 \mu \mathrm{m}$ pore-size membrane of regenerated cellulose, deionized water or THF was used to dilute the latex sample. Solutions were analyzed without further filtration to ensure that undesired populations were not removed. Data were analyzed by the generalpurpose non-negative least squares (NNLS) method. The typical accuracy for these measurements was $10-15 \%$.
General procedure for the phosphine ligand complexation to [Rh(acac)(CO) $)_{2}$. The $[\mathrm{Rh}(\mathrm{acac})(\mathrm{CO})(\mathrm{TPP} @ \mathrm{CCM}-2)]$ latex $(100 \% \mathrm{Rh}$ loading to the phosphine functions) was prepared as reported previously. ${ }^{[3]}$ ${ }^{31} \mathrm{P}\left\{{ }^{1} \mathrm{H}\right\} \mathrm{NMR}\left(162 \mathrm{MHz}, \mathrm{CDCl}_{3}, 298 \mathrm{~K}\right): \delta 47.6$ (d, J = $\left.175 \mathrm{~Hz}\right)$. The same procedure was used to prepare the TPP@CCM-1 and TPP@CCM-3 latexes $100 \%$ loaded with the $[\mathrm{Rh}(\mathrm{acac})(\mathrm{CO})]$ fragment, by adjusting the amount of precursor $\left[\mathrm{Rh}(\mathrm{acac})(\mathrm{CO})_{2}\right]$ complex to a slight excess (ca. 1.01 equiv) relative to the amount of phosphine functions as detailed in Table 1. The ${ }^{31} \mathrm{P}\left\{{ }^{1} \mathrm{H}\right\}$ NMR resonances of the different latexes were identical.

Interparticle metal exchange study involving $100 \%$ [Rh(acac)(CO)]loaded polymer latex and $\mathrm{Rh}$-free polymer latex. (a) At the natural $\mathrm{pH}$, using the TPP@CCM-2 particles. The two starting latexes were prepared independently by diluting $1.5 \mathrm{~mL}$ of TPP@CCM-2 $(0.177 \mathrm{mmol}$ of TPP, $0.0885 \mathrm{mmol}$ of MAA) with $\mathrm{D}_{2} \mathrm{O}(4.5 \mathrm{~mL})$. The final $\mathrm{pH}$ of the aqueous phase was 5.5. One of these two samples was charged with $\left[\mathrm{Rh}(\mathrm{acac})(\mathrm{CO})_{2}\right](100 \%$ loading) as described above. The second sample was swollen with the same amount of toluene used for the first sample in order to obtain the same concentration of particles. Equivalent volumes of these two samples were then directly mixed in an NMR tube under argon and the resulting mixture was monitored by ${ }^{31} \mathrm{P}\left\{{ }^{1} \mathrm{H}\right\}$ NMR spectroscopy (see Results and Discussion).

(b) Under basic conditions, using the TPP@CCM-2 particles. This procedure was identical to that described in section (a), except that the two starting latexes, one of which was charged with $\left[\mathrm{Rh}(\mathrm{acac})(\mathrm{CO})_{2}\right](100 \%$ loading) were prepared from $0.5 \mathrm{~mL}$ of TPP@CCM-2 $(0.06 \mathrm{mmol}$ of TPP, $0.03 \mathrm{mmol}$ of MAA) with $\mathrm{D}_{2} \mathrm{O}(1 \mathrm{~mL})$. The Rh-charged latex was prepared by adding a slight excess of $\left[\mathrm{Rh}(\mathrm{acac})(\mathrm{CO})_{2}\right]$ (ca. 1.1 equiv) to insure quantitative complexation of the phosphine functions, then the excess metal was removed by cannulating away the residual toluene phase following by washing the aqueous phase with fresh toluene several times until the washings were colorless. $60 \mu \mathrm{L}$ of a concentrated $\mathrm{NaOH}$ solution $(10 \mathrm{~N}, 0.6 \mathrm{mmol})$ was added to each latex to adjust the final $\mathrm{pH}$ to 13.6 before mixing in the NMR tube.

Interparticle metal exchange study involving [Rh(acac)(CO)(TPP@CCM)] and TPP@CCM in the presence of NaCl. Stock solutions of TPP@CCM-2 (Table 1) and [Rh(acac)(CO)(TPP@CCM-2)] (100\% metal loading) were prepared from $0.5 \mathrm{ml}$ of latex (0.06 mol of DPPS) diluted into $\mathrm{D}_{2} \mathrm{O}(1 \mathrm{ml})$. To each sample was added $120 \mu \mathrm{L}$ of a concentrated $\mathrm{NaCl}$ solution $(5 \mathrm{~N}, 0.6 \mathrm{mmol})$. These two latexes were then directly mixed in equimolar amounts in an NMR tube under argon. The resulting solution was monitored by ${ }^{31} \mathrm{P}\left\{{ }^{1} \mathrm{H}\right\}$ NMR spectroscopy.

Reaction between $\left[\mathrm{Rh}(\mathrm{acac})(\mathrm{CO})_{2}\right]$, TPP and alkali metal reagents in toluene/water. Stock solutions were prepared as follows. A partially deuterated toluene solution contains $\left[\mathrm{Rh}(\mathrm{acac})(\mathrm{CO})_{2}\right](120 \mathrm{mg}, 0.46 \mathrm{~mol})$, TPP (235 mg, $0.90 \mathrm{mmol})$ and compound $\mathrm{CpFe}\{\mathrm{n}-1,2-$ $\left.\mathrm{C}_{5} \mathrm{H}_{3}\left(\mathrm{PPh}_{2} \mathrm{~S}\right)\left(\mathrm{CH}_{2} \mathrm{OCH}_{2}-\mathrm{C}_{6} \mathrm{H}_{4}-p-\mathrm{CH}_{3}\right)\right\}^{[21]}(23.4 \mathrm{mg}, 0.044 \mathrm{mmol}$ ) (used as internal standard) in $15 \mathrm{~mL}$ of solvent composed of $7.5 \mathrm{~mL}$ of $\mathrm{C}_{6} \mathrm{D}_{5} \mathrm{CD}_{3}$ and $7.5 \mathrm{~mL}$ of regular toluene. Aqueous solutions of $\mathrm{NaOH}(10 \mathrm{~N}), \mathrm{KOH}(10 \mathrm{~N})$, $\mathrm{NaCl}(5 \mathrm{~N})$ and $\mathrm{KCl}(4.6 \mathrm{~N})$ were also prepared separately in degassed and deionized water. These solutions were used in the following experiments.

a) Without additives. In a Schlenk tube, $2 \mathrm{~mL}$ of degassed and deionized water $(2 \mathrm{~mL})$ was treated with the $\mathrm{NaOH}$ stock solution $(80 \mu \mathrm{L})$ or with the $\mathrm{NaCl}$ stock solution $(160 \mu \mathrm{L})(0.80 \mathrm{mmol}$ of sodium reagent). The toluene stock solution $(2 \mathrm{~mL}, 0.062 \mathrm{mmol})$ was then added and the biphasic mixture was vigorously stirred at room temperature (final $[\mathrm{NaX}] /[\mathrm{Rh}]=13$ ). Aliquots were withdrawn from the organic layer after $10 \mathrm{~min}$ and after $1 \mathrm{~h}$ and directly used for the NMR analyses. 
b) With PEO $_{1000}$. This experiment was run as described in the above section, with the additional introduction of $\mathrm{PEO}_{1000}(17.6 \mathrm{mg}$, ca. $0.40 \mathrm{mmol}$ of EO units), to the aqueous phase before introduction of the toluene stock solution.

c) With 18-crown-6. Two different experiments were run as described in part (a), with the additional introduction of 18-crown-6. Furthermore, because of the lower concentration of the $\mathrm{KCl}$ stock solution, its added volume $(170 \mu \mathrm{L})$ was adjusted to obtain the same $0.80 \mathrm{mmol}$ amount of the inorganic reagent in the final mixture. In the first experiment, $0.17 \mathrm{~mL}$ (211 $\mathrm{mg}, 0.80 \mathrm{mmol}$ ) of the crown ether were added to the aqueous phase before introduction of the toluene stock solution $([18$-crown- 6$] /[\mathrm{K}]=1)$. In the second experiment the crown ether amount was larger: $0.85 \mathrm{~mL}(1.054$ g, $4.0 \mathrm{mmol} ;[18-$ crown-6]/[K] = 5).

\section{Acknowledgements}

We are grateful to the Agence Nationale de la Recherche (ANR) for support of this work through grant "BIPHASNANOCAT" (ANR11-BS07-025-01). Additional support from the Centre National de la Recherche Scientifique (CNRS) and from the Institut Universitaire de France (IUF) is also gratefully acknowledged. We thank Dr. K. Roger for helpful discussion.

Keywords: $\mathrm{P}$ ligands $•$ polymers $\bullet$ rhodium $\bullet$ nanostructures $•$ amphiphilic core-shell star polymers $\bullet$ nanoreactor $\bullet$ coordination chemistry

[1] a) F. D. Evans and H. Wennerström, The Colloidal Domain: Where Physics, Chemistry, Biology, and Technology Meet, 2nd Edition, Wiley-VCH, Weinheim, 1999, p; b) L. Taisne, P. Walstra and B. Cabane, Journal of Colloid and Interface Science 1996, 184, 378-390.

[2] K. Roger, U. Olsson, R. Schweins and B. Cabane, Angew. Chem. Int. Ed. Engl. 2015, 54, 1452-1455

[3] X. Zhang, A. F. Cardozo, S. Chen, W. Zhang, C. Julcour, M. Lansalot, J.-F Blanco, F. Gayet, H. Delmas, B. Charleux, E. Manoury, F. D'Agosto and R. Poli, Chem. Eur. J. 2014, 20, 15505-15517.

[4] A. F. Cardozo, C. Julcour, L. Barthe, J.-F. Blanco, S. Chen, F. Gayet, E. Manoury, X. Zhang, M. Lansalot, B. Charleux, F. D'Agosto, R. Poli and H. Delmas, J. Catal. 2015, 324, 1-8.

[5] a) S. Chen, A. F. Cardozo, C. Julcour, J.-F. Blanco, L. Barthe, F. Gayet, B. Charleux, M. Lansalot, F. D'Agosto, H. Delmas, E. Manoury and R. Poli, Polymer 2015, 72, 327-335; b) R. Poli, S. Chen, X. Zhang, A. Cardozo, M. Lansalot, F. D'Agosto, B. Charleux, E. Manoury, F. Gayet, C. Julcour,
J.-F. Blanco, L. Barthe and H. Delmas, ACS Symp. Ser. 2015, 1188, 203 220.

[6] a) A. Lu and R. K. O'Reilly, Curr. Opin. Biotech. 2013, 24, 639-645; b) P. Cotanda, N. Petzetakis and R. K. O'Reilly, MRS Communications 2012, 2, 119-126.

[7] a) G. Oehme, Appl. Homogeneous Catal. Organomet. Compd. (2nd Ed.) 2002, 2, 835-841; b) V. C. Reinsborough, Interfacial Catal. 2003, 377390; c) M. N. Khan, Micellar Catalysis, CRC Press, 2006, p. 464 pp.

[8] A. D. Levins, X. F. Wang, A. O. Moughton, J. Skey and R. K. O'Reilly, Macromolecules 2008, 41, 2998-3006.

[9] a) Y. Liu, V. Pinon and M. Weck, Polym. Chem. 2011, 2, 1964-1975; b) Y. Liu, Y. Wang, Y. F. Wang, J. Lu, V. Pinon and M. Weck, J. Am. Chem. Soc. 2011, 133, 14260-14263.

[10] a) T. Terashima, M. Kamigaito, K.-Y. Baek, T. Ando and M. Sawamoto, J. Am. Chem. Soc. 2003, 125, 5288-5289; b) T. Terashima, M. Ouchi, T. Ando, M. Kamigaito and M. Sawamoto, J. Polym. Sci., Polym. Chem. 2006, 44, 4966-4980; c) T. Terashima, M. Ouchi, T. Ando, M. Kamigaito and M. Sawamoto, Macromolecules 2007, 40, 3581-3588; d) T. Terashima, M. Ouchi, T. Ando and M. Sawamoto, J. Polym. Sci., Polym. Chem. 2010, 48, 373-379; e) T. Terashima, M. Ouchi, T. Ando and M. Sawamoto, Polym. J. 2011, 43, 770-777; f) T. Terashima, M. Ouchi, T. Ando and M. Sawamoto, J. Polym. Sci., Polym. Chem. 2011, 49, 10611069; g) T. Terashima in Polymer Microgels for Catalysis, (Ed. H. F. Mark), John Wiley \& Sons, Inc., 2013, p 10.1002/0471440264.pst0471440590.

[11] J. M. Harris in Poly(Ethylene Glycol) Chemistry: Biotechnical and Biomedical Applications, Vol. Springer Science \& Business Media, New York, 1992.

[12] J. Zhang and N. A. Peppas, Macromolecules 2000, 33, 102-107.

[13] T. Ikawa, K. Abe, K. Honda and E. Tsuchida, J. Polym. Sci., Polym. Chem. 1975, 13, 1505-1514.

[14] H. Dong, H. Du and X. Qian, J. Phys. Chem. B 2009, 113, 12857-12859.

[15] C. Heitz, M. Rawiso and J. Francois, Polymer 1999, 40, 1637-1650.

[16] S. Chen, E. Manoury and R. Poli, Eur. J. Inorg. Chem. 2014, 5820-5826.

[17] a) L. Vaska and J. Peone, Chem. Commun. 1971, 418-419; b) I. J. Colquhoun and W. McFarlane, Journal of Magnetic Resonance 1982, 46 525-528.

[18] J. Chatt and B. L. Shaw, J. Chem. Soc. A 1966, 1437-1442.

[19] B. Parker, B. Immaraporn and A. J. Gellman, Langmuir 2001, 17, 66386646.

[20] a) J. G. Lee, J. Ahner, D. Mocuta, S. Denev and J. T. Yates, J. Chem. Phys. 2000, 112, 3351-3357; b) B. Immaraporn, P. P. Ye and A. J. Gellman, J. Phys. Chem. B 2004, 108, 3504-3511.

[21] S. Bayda, A. Cassen, J.-C. Daran, C. Audin, R. Poli, E. Manoury and E. Deydier, J. Organomet. Chem. 2014, 772-773, 258-264. 


\section{Entry for the Table of Contents}

\section{FULL PAPER}

The molecular dynamics of corecross-linked micelle (CCM) latexes is revealed by NMR studies of interparticle metal migration at different $\mathrm{pH}$; the peculiar interface structuring of these polymeric nanoreactors accounts for the rapid vectorization of ionic compounds from the aqueous phase to the hydrophobic core.

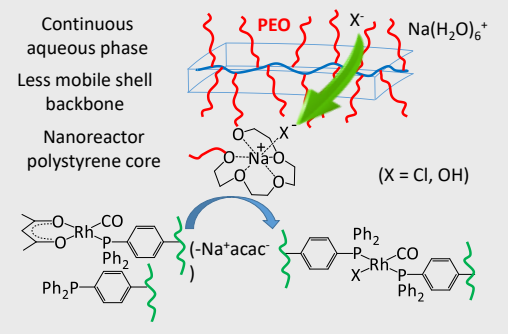

Si Chen, Florence Gayet, Eric Manoury, Ahmad Joumaa, Muriel Lansalot, Franck D'Agosto and Rinaldo Poli*

Page No. - Page No.

Coordination chemistry inside polymeric nanoreactors: interparticle metal exchange processes and ionic compound vectorization in phosphine-functionalized amphiphilic polymer latexes 